\title{
Combined Vitrectomy With Macular Buckling In High Myopic Eyes With Macular Hole Retinal Detachment: A Pilot Study Of A Novel Snail-Tipped Exoplant
}

This article was published in the following Dove Press journal: Clinical Ophthalmology

\section{Hae Jung Sun (D) \\ Charm Kim (i) \\ Kibum Park (D) \\ Sung Jin Lee (D)}

Department of Ophthalmology, Soonchunhyang University College of Medicine, Soonchunhyang University Hospital, Seoul, South Korea
Correspondence: Sung Jin Lee Department of Ophthalmology, Soonchunhyang University College of Medicine, Soonchunhyang University Hospital, \#59 Daesagwan-ro, Yongsan-gu, Seoul 140-743, South Korea

Tel +82-2-709-9355

Fax +82-2-710-3196

Email wismile@schmc.ac.kr
Purpose: To evaluate the efficacy of a novel snail-tipped exoplant for macular buckling combined with vitrectomy in high myopic eyes with macular hole retinal detachment.

Patient and methods: A novel exoplant was simply prepared with a $5 \times 3 \mathrm{~mm}$ silicone sponge strengthened in the center with a malleable titanium plate. One end was bent to make a rolled tip like a snail shell to be placed under the macula. Combined vitrectomy with macular buckling using this exoplant was performed in eight consecutive cases. The long arm of the exoplant was manipulated manually to fit the curvature of the eyeball and the length was trimmed appropriately after scleral suturing of the exoplant.

Results: Retinal reattachment was achieved in all cases (100\%) and macular hole closure was confirmed in 6 eyes (75\%). The mean best-corrected visual acuity improved from $1.53 \pm$ $0.73 \operatorname{LogMAR}$ preoperatively to $1.14 \pm 0.59$ LogMAR to postoperatively $(p=0.063)$. The mean pre- and postoperative AL was $28.44 \pm 1.86 \mathrm{~mm}$ and $27.60 \pm 1.83 \mathrm{~mm}$, respectively ( $p=0.016$ ). The mean follow-up period was 15.4 months and no buckle-related complications such as diplopia, infection or exposure of the exoplant were noticed during the period. Conclusion: This exoplant could easily be prepared with readily available materials in the operating room and it was well tolerated with favorable anatomic results in high myopic eyes. Further studies of increased number of patients with long-term follow-up will be necessary.

Keywords: exoplant, high myopia, macular buckling, macular hole retinal detachment, posterior staphyloma

\section{Introduction}

Macular hole retinal detachment (MHRD) occurs mostly in high myopic eyes. ${ }^{1}$ The abnormal elongation of the eyeball causes thinning of the retina, choroid, and the sclera and increased stretching of the posterior pole causes bulging of the sclera, which is called a posterior staphyloma (PS). Progressive chorioretinal atrophy along with the tangential tractions caused by the vitreous cortex and internal limiting membrane (ILM) within the PS results in macular hole (MH) development. ${ }^{2,3} \mathrm{~A}$ $\mathrm{MH}$ opening may result in further decrease in visual acuity with the influx of the liquefied vitreous into the subretinal space, causing MHRD.

Since 1982, when Gonvers and Machemer first introduced pars plana vitrectomy (PPV) for the treatment of MHRD, ${ }^{4}$ PPV with or without ILM peeling and gas tamponade has become the treatment of choice for MH or MHRD surgery. PPV releases tangential and centripetal traction caused by the vitreous cortex, ${ }^{5}$ but there 
still exists vascular traction and anteroposterior traction caused by the PS that stretches the retina. Although macular buckling (MB) was first reported in $1957,{ }^{6}$ which was the only method of treatment for MHRD for over 20 years before the era of PPV, it was not a popular surgical procedure because of its surgical difficulties and increased risk of surgical complications. Despite the difficulties, MB has the advantage of releasing the anteroposterior traction due to the PS by reshaping the posterior scleral wall from concave to a flat or even convex configuration and remodels the disproportion between the retina and the sclera, supporting the posterior scleral wall. ${ }^{7}$

Recently, Alkabes and Mateo published a 16-year review of $\mathrm{MB}$ technique performed in myopic eyes. ${ }^{8}$ Diverse shapes of exoplants made of many different types of materials were described and MB with or without PPV showed superior surgical results to PPV alone. We performed MB combined with PPV in eyes with MHRD and PS with a modified exoplant which tip was rolled at one end to shape like a snail shell. The purpose of this report is to introduce this newly modified exoplant for MB and to report the safety and efficacy of the surgical approach.

\section{Materials And Methods}

We retrospectively reviewed the records of 8 eyes of 8 patients who underwent combined surgery of MB with PPV due to MHRD and PS between March 2016 and April 2018. This retrospective study was approved by the institutional review board of Soonchunhyang University Seoul Hospital (IRB file no. 2018-10-014). The study design and data accumulation were done in adherence to the tenets of the Declaration of Helsinki. All patients were informed about the risks and benefits of the surgical procedures prior to the surgery and each patient had given written informed consent. All surgeries were performed by one single surgeon (SJL).

All patients underwent a complete ophthalmic evaluation pre- and postoperatively, including measurement of best-corrected visual acuity (BCVA), biomicroscopy of the anterior segment, mydriatic fundus examination, and fundus photography. Axial length (AL) measurement was performed preand postoperatively using laser-assisted optical biometer (IOL master 500, Carl Zeiss Meditec, Jena, Germany) and A/B scan ultrasonography (USG) (HiScan system, Optikon SpA, Rome, Italy). Spectral domain optical coherence tomography (OCT; Spectralis HRA+OCT, Heidelberg Engineering, Dossenheim, Germany) B-scans were acquired through dilated pupils pre- and postoperatively to evaluate the status of $\mathrm{MH}$ and a single examiner (HJS) judged the complete closure of $\mathrm{MH}$ and retinal reattachment.

\section{Surgical Procedures}

Under general anesthesia, $120^{\circ}$ superotemporal conjunctival peritomy was done and bridle suture was passed under the superior rectus and the lateral rectus muscle with 4-0 black silk. Phacoemulsification with intraocular lens (IOL) implantation was performed in phakic eyes. PPV was done with posterior hyaloid dissection and ILM peeling. Preservative-free triamcinolone (TA) agent $\left(\mathrm{MaQaid}^{\circledR}\right.$, Wakamoto Pharmaceutical Co., Ltd., Tokyo, Japan) was used for chromovitrectomy for complete removal of the vitreous, since vitreoschisis is common in high myopic eyes. The triamcinolone particles adhered on the surface of the ILM assist membrane peeling by better visualizing the ILM. Peripheral vitreous shaving was done with scleral depression.

The exoplant for MB was easily prepared in the operating room with a $5 \times 3 \mathrm{~mm}$ silicone sponge (506 silicone sponge, MIRA, USA) and a malleable titanium plate (0.5 mm thick, 20 holes, titanium adoption plate, MatrixMIDFACETM Plate, Depuy Synthes, West Chester, PA, USA). A tunnel was made into the silicone sponge with a 20-gauge microvitreoretinal (MVR) blade and the titanium plate was inserted into the tunnel. When the titanium plate reached the end of the silicone sponge, the tip was rolled to a snail shell shape (Figure 1). By this procedure, the short arm of the exoplant was thickened in height to threefold thickness of the long arm and the long arm was bent to fit the curvature of the eyeball. Rotating the eyeball inferonasally, the exoplant was inserted superotemporally to the posterior of the globe to reach the macula. The buckle height was adjusted under direct visualization of the location of the buckle through the vitrectomy lens with the illuminator inserted through the trocar. The long arm of the exoplant was fixed to the sclera with a mattress suture posterior to the muscle insertion sites using 5-0 Dacron suture (Alcon, USA). The location was checked once again and a second mattress suture was fixed posterior to the first mattress suture. The remnant length of the exoplant was trimmed using a plate cutter and the titanium plate was cut more deeply into the silicone sponge to hide its end into the sponge. Figure 2 is a schematic drawing to explain the location of the exoplant.

Fluid air exchange was done followed by $14 \%$ perfluropropane $\left(\mathrm{C}_{3} \mathrm{~F}_{8}\right)$ gas or silicone oil tamponade. After 

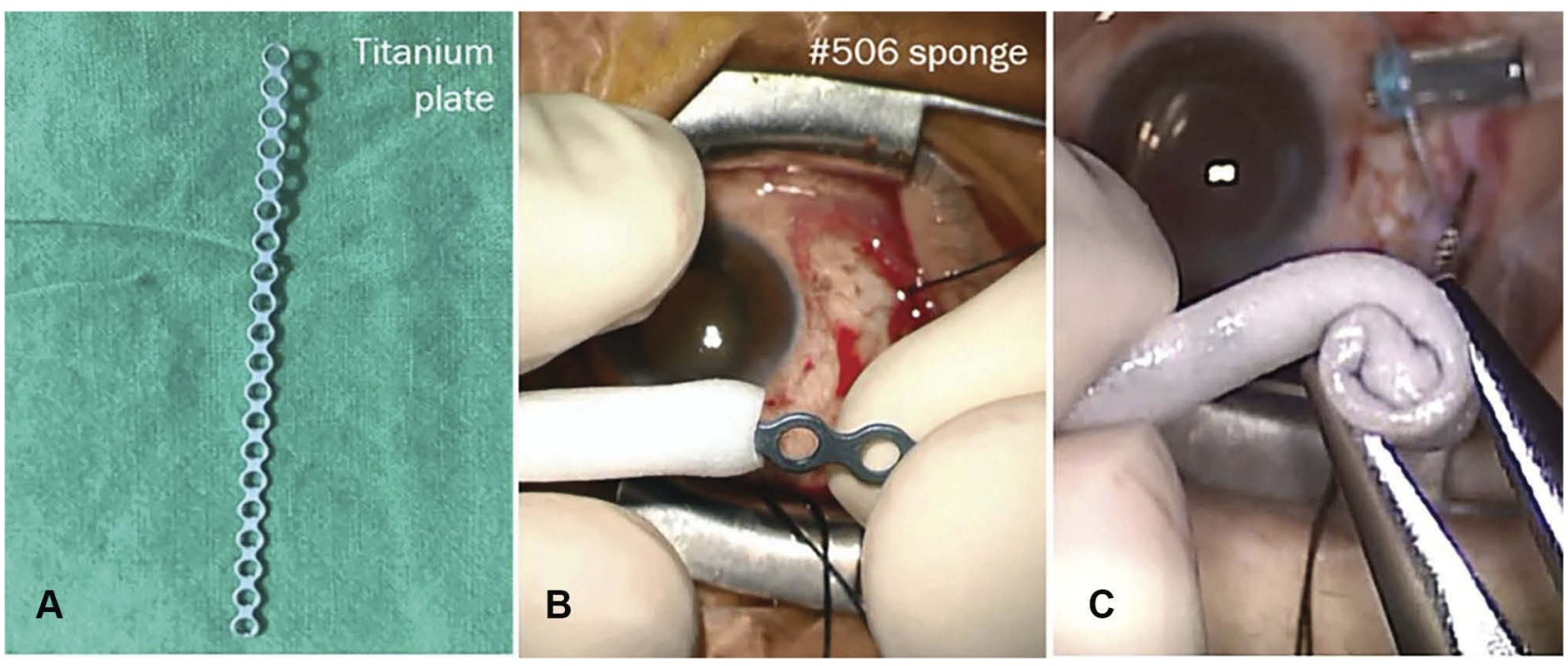

Figure I Preparation of the snail-tipped exoplant. (A) A malleable titanium plate $\left(0.5 \mathrm{~mm}\right.$ thick, 20 holes, titanium adaption plate, MatrixMIDFACE ${ }^{\mathrm{TM}}$ Plate, Depuy Synthes, West Chester, PA, USA) was used to strengthen the exoplant. (B) After tunneling the silicone sponge (506 silicone sponge, MIRA, USA) with a 20-gauge MVR blade and the titanium plate was inserted into the tunnel. (C) When the titanium plate was reached to the end of the silicone sponge, the tip was rolled to a snail shell shape.

removal of the trocars, the conjunctiva was approximated with 8-0 Vicryl suture (Ethicon; Johnson and Johnson, Livingston, UK). The patients were instructed to keep face-down position for 2 weeks postoperatively. A stepwise approach of this surgical procedure is shown in Figure 3 for better understanding. Also, a supplementary video is provided to show the whole surgical procedure.

\section{Statistical Analysis}

The BCVA was recorded as decimal values and it was converted to the logarithm of the minimal angle of resolution

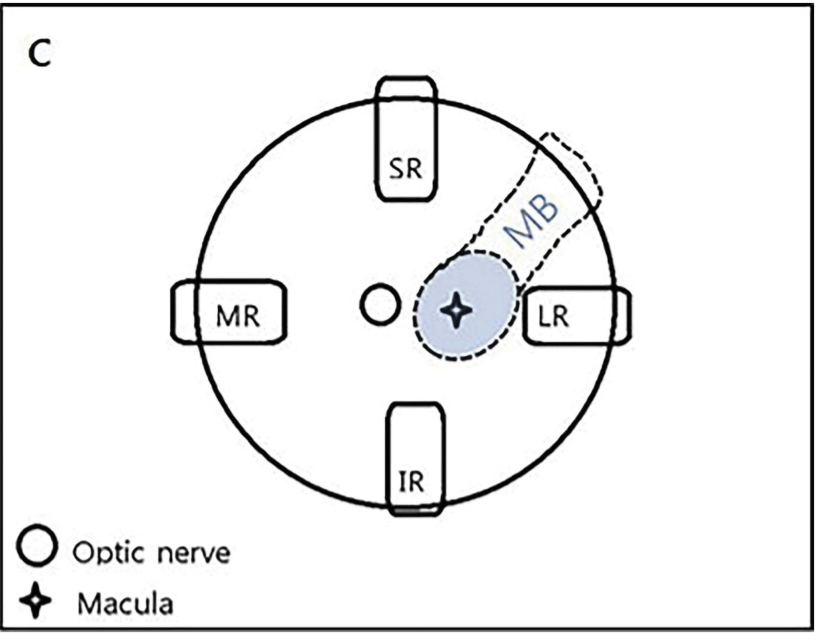

Figure 2 Location of the exoplant. A schematic drawing shows the location of the exoplant in a left eye. The exoplant is inserted superotemporally to reach the macular area.

Abbreviations: IR, inferior rectus muscle; $L R$, lateral rectus muscle; $M B$, macular buckle; MR, medial rectus muscle; SR, superior rectus muscle.
(LogMAR) units for statistical analysis. Hand movement perception was converted to a LogMAR value of 3.0. Preand final postoperative BCVA and changes in AL measurements were compared using Wilcoxon signed-ranks test and a $P$-value $<0.05$ was considered statistically significant using SPSS for Windows version 25 (SPSS, Inc, Chicago, IL).

\section{Results}

The pre- and postoperative clinical characteristics of the patients are described in Table 1 . The mean age of the 8 patients ( 7 female, 1 male) was $65.75 \pm 6.81$ years (range 55 to 74). 25-gauge PPV was done in all but one eye (case 8 ) which was performed using 20-gauge PPV in a patient who had previously undergone PPV due to retinoschisis and $\mathrm{MH}$. The 20-gauge system was used in this recurred case for more thorough shaving of the peripheral vitreous since it is easier to control a more rigid outcome and it has lower risks of making iatrogenic retinal breaks. Combined PPV with cataract surgery was performed in four eyes and among them one eye had previously implanted phakic IOL which was removed for cataract surgery (case 7). Additional scleral encircling was performed in two eyes (case 6 and case 8 ) that had multiple peripheral retinal breaks with subretinal fluid extended anterior to the equator. Silicone oil was injected in 3 eyes, and $\mathrm{C}_{3} \mathrm{~F}_{8}$ gas was injected in 5 eyes as tamponade, respectively. The mean follow-up period was 15.4 months, ranging from 4 to 30 months. Postoperative BCVA improved in 5 eyes, maintained in 2 eyes and decreased in 1 eye. The mean pre- and 


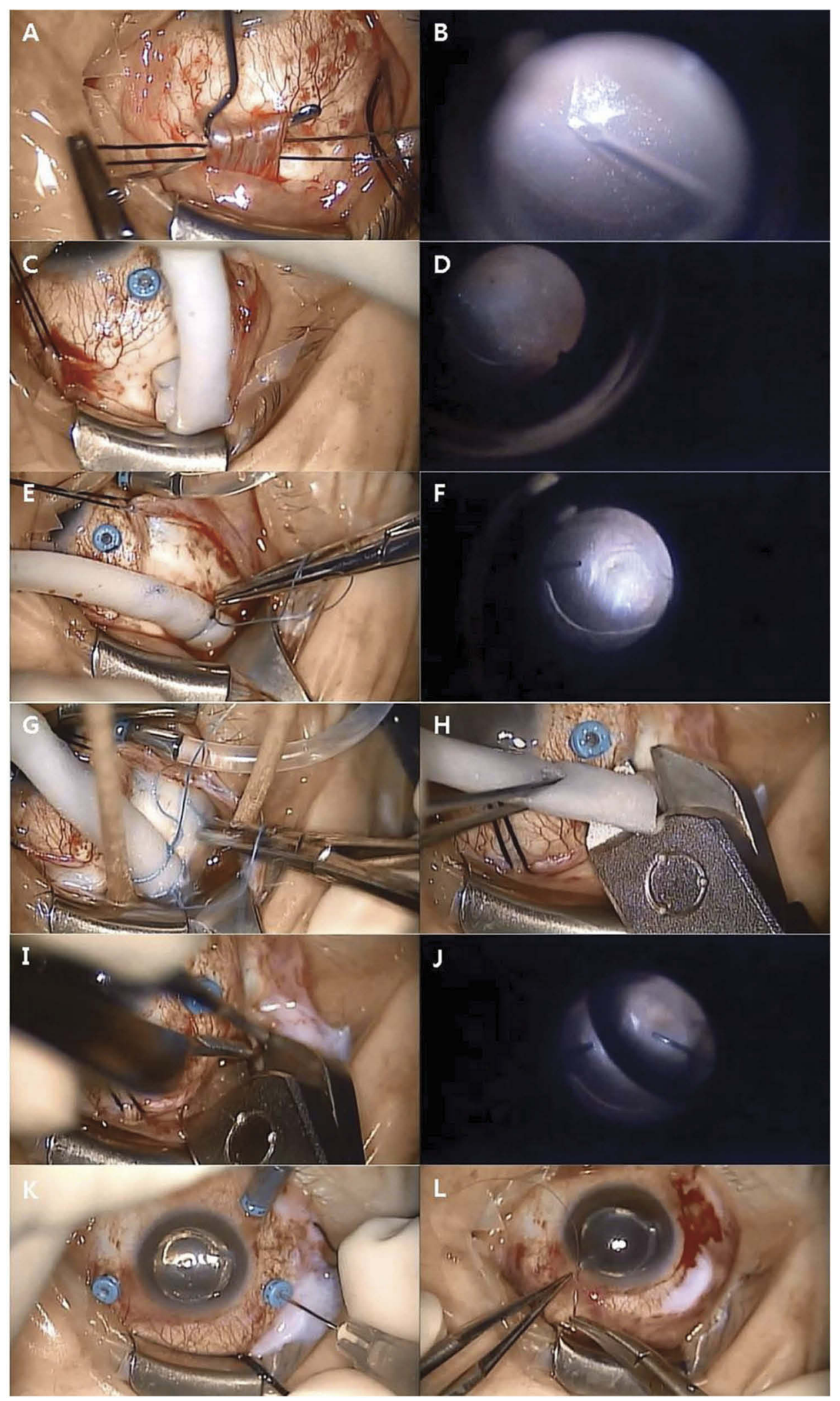

Figure 3 Stepwise approach of the surgical procedure. (A) After $120^{\circ}$ superotemporal conjunctival peritomy, bridle suture was passed under the superior rectus and the lateral rectus muscle. (B) 25-gauge PPV and ILM peeling using MaQaid ${ }^{\circledR}$ for chromovitrectomy was performed. (C) Rotating the eyeball inferonasally, the prepared exoplant was inserted superotemporally to the posterior of the globe to reach the macula. (D) The buckle height and location was adjusted under direct visualization through the vitrectomy lens. (E) The long arm of the exoplant was fixed with a mattress suture posterior to the muscle insertion sites. (F) The buckle height and location was checked once again. (G) A second mattress suture was fixed posterior to the first mattress suture. (H) The remnant length of the exoplant was trimmed using a plate cutter. (I) The titanium plate was cut more deeply into the silicone sponge to hide its end into the sponge. (J) Fluid air exchange and subretinal fluid drainage was done. (K) Gas or silicone oil tamponade was performed. (L) Finally, the conjunctiva was approximated with 8-0 Vicryl suture. 
Table I Demographic And Other Baseline Characteristics Of Patients Before And After Surgery

\begin{tabular}{|l|l|l|l|l|l|l|l|l|l|l|}
\hline Case & Sex & $\begin{array}{l}\text { Age } \\
\text { (y) }\end{array}$ & $\begin{array}{l}\text { Preop AL } \\
(\mathbf{m m})\end{array}$ & $\begin{array}{l}\text { Postop AL } \\
(\mathbf{m m})\end{array}$ & $\begin{array}{l}\text { Preop BCVA } \\
\text { (Snellen) }\end{array}$ & $\begin{array}{l}\text { Final BCVA } \\
\text { (Snellen) }\end{array}$ & $\begin{array}{l}\text { Intraocular } \\
\text { Tamponade Material }\end{array}$ & $\begin{array}{l}\text { RD } \\
\text { Closure }\end{array}$ & $\begin{array}{l}\text { Hole } \\
\text { (Months) }\end{array}$ \\
\hline I & $\mathrm{F}$ & 71 & 27.66 & 26.28 & 0.02 & 0.02 & $\mathrm{C}_{3} \mathrm{~F}_{8}$ & + & - & 30 \\
2 & $\mathrm{M}$ & 68 & 28.50 & 27.00 & 0.1 & 0.2 & $\mathrm{C}_{3} \mathrm{~F}_{8}$ & + & + & 24 \\
3 & $\mathrm{~F}$ & 75 & 27.71 & 26.50 & 0.05 & 0.2 & $\mathrm{C}_{3} \mathrm{~F}_{8}$ & + & + & 4 \\
4 & $\mathrm{~F}$ & 61 & 29.83 & 28.86 & 0.1 & 0.4 & $\mathrm{C}_{3} \mathrm{~F}_{8}$ & + & + & 24 \\
5 & $\mathrm{~F}$ & 74 & 26.24 & 26.17 & 0.03 & 0.08 & SO & + & + & 14 \\
6 & $\mathrm{~F}$ & 62 & 33.54 & - & 0.01 & 0.01 & SO & + & + & 7 \\
7 & $\mathrm{~F}$ & 55 & 27.30 & 27.17 & 0.2 & 0.16 & $\mathrm{C}_{3} \mathrm{~F}_{8}$ & + & + & 11 \\
8 & $\mathrm{~F}$ & 60 & 31.83 & 31.19 & $\mathrm{HM}$ & 0.02 & SO & & + & - \\
\hline
\end{tabular}

Abbreviations: Preop, preoperative; Postop, postoperative; AL, axial length; BCVA, best-corrected visual acuity; HM, hand motion; $\mathrm{C}_{3} \mathrm{~F}_{8}$, octafluoropropane; SO, silicone oil; RD, retinal detachment; +, present; -, not present.

postoperative BCVA was $1.53 \pm 0.73 \operatorname{LogMAR}$ and $1.14 \pm$ 0.59 LogMAR, respectively $(p=0.063)$. The mean preoperative AL of the 8 eyes was $29.08 \pm 2.49 \mathrm{~mm}$ (range 26.24 to 33.54). Postoperative AL was measured in 7 eyes (except case 6 who was lost for follow-up) and the mean pre- and postoperative AL was $28.44 \pm 1.86 \mathrm{~mm}$ and $27.60 \pm$ $1.83 \mathrm{~mm}$, respectively $(p=0.016)$. The average amount of AL shortening after MB was $0.84 \pm 0.58 \mathrm{~mm}$.

Retinal reattachment was achieved in all cases $(100 \%)$ and $\mathrm{MH}$ closure was confirmed in 6 eyes (75\%). Postoperative OCT of the 8 patients showed retinal reattachment with convex configuration or flattening of the posterior pole. Representative images are shown in Figures 4-6. Eyes that had gas tamponade were able to check the postoperative B-scan USG and PS seen on preoperative B-scan USG was corrected with reshaping of the eyeball postoperatively (Figure 7). Eyes filled with silicone oil were still remained at the time of most recent follow-up.

No buckle-related complications such as diplopia, infection or exposure of the exoplant or recurrence of MHRD occurred during the follow-up period. Any loosening of the buckle effect was not noticed, the contour of the posterior pole on postoperative OCTs was stable throughout the follow-up period. One eye developed corneal ulcer 4 months after the surgery. The ulcerative lesion was located at the superior limbal area where corneal suture was placed. Acinetobacter baumannii/ haemolyticus was the causative agent. After removal of the corneal suture and fortified antibiotic eyedrops treatment, the ulcer site was healed with remnant anterior stromal opacity. Corneal ulcer was not related to the exoplant since the buckle area was free of any inflammation or infection.

\section{Discussion}

MB was a conventional surgical method for MRHD before the era of PPV. PPV with intravitreal gas/silicone oil tamponade is a preferred surgical option nowadays because $\mathrm{MB}$ is a challenging procedure. Difficulty to visualize the back of the globe to localize the macular hole and the fear of hazardous complications that may happen during surgery by damaging the extraocular structures while manipulating the exoplant or perforation of the globe by scleral sutures make retinal surgeons to avoid MB. PPV with ILM peeling can remove the tangential and centripetal tractions caused by the vitreous cortex, epiretinal membrane (ERM) or ILM. ${ }^{9}$ Vitreoschisis is quite common in myopic eyes where excess vitreous liquefaction for the degree of vitreoretinal adhesion can cause anomalous posterior vitreous detachment (PVD). ${ }^{10}$ ILM peeling could be a confirmatory procedure to remove all the vitreous from the fovea but still incomplete PPV may induce surgical failure due to preretinal fibrosis and proliferative vitreoretinopathy. Chromovitrectomy using TA aids detection of the transparent vitreous and any ERM remnants. A study comparing results of TA-assisted PPV to PPV without TA, eyes that underwent TAassisted PPV had lower rate of reoperation due to preretinal fibrosis. ${ }^{11}$ In our study, we performed PPV using preservativefree TA powder in all eyes to minimize any complications related to incomplete PPV. Nakanishi et $\mathrm{al}^{9}$ performed PPV for MHRD to find out the prognostic factors associated with the surgical outcome and AL was the only factor that had a statistically significant association with initial reattachment. Therefore, MB procedure by reshaping the posterior scleral wall, which is the only method to correct the PS to shorten the $\mathrm{AL}$ in high myopic eyes, has benefits in MHRD surgery.

Various materials were used as exoplants for MB. Donor sclera, silicone sponge, wire/malleable titanium stent strengthened silicone sponge, silicone-coated polymethyl methacrylate, solid silicone band, silicone plate containing metal wire (Ando plombe) have been used as materials for $\mathrm{MB}^{8}$ Recently, Wu et $\mathrm{al}^{12}$ used polytetrafluoroethylene (Gore-Tex) vascular graft for $\mathrm{MB}$ and fiber-optic light assisted $\mathrm{MB}$ 


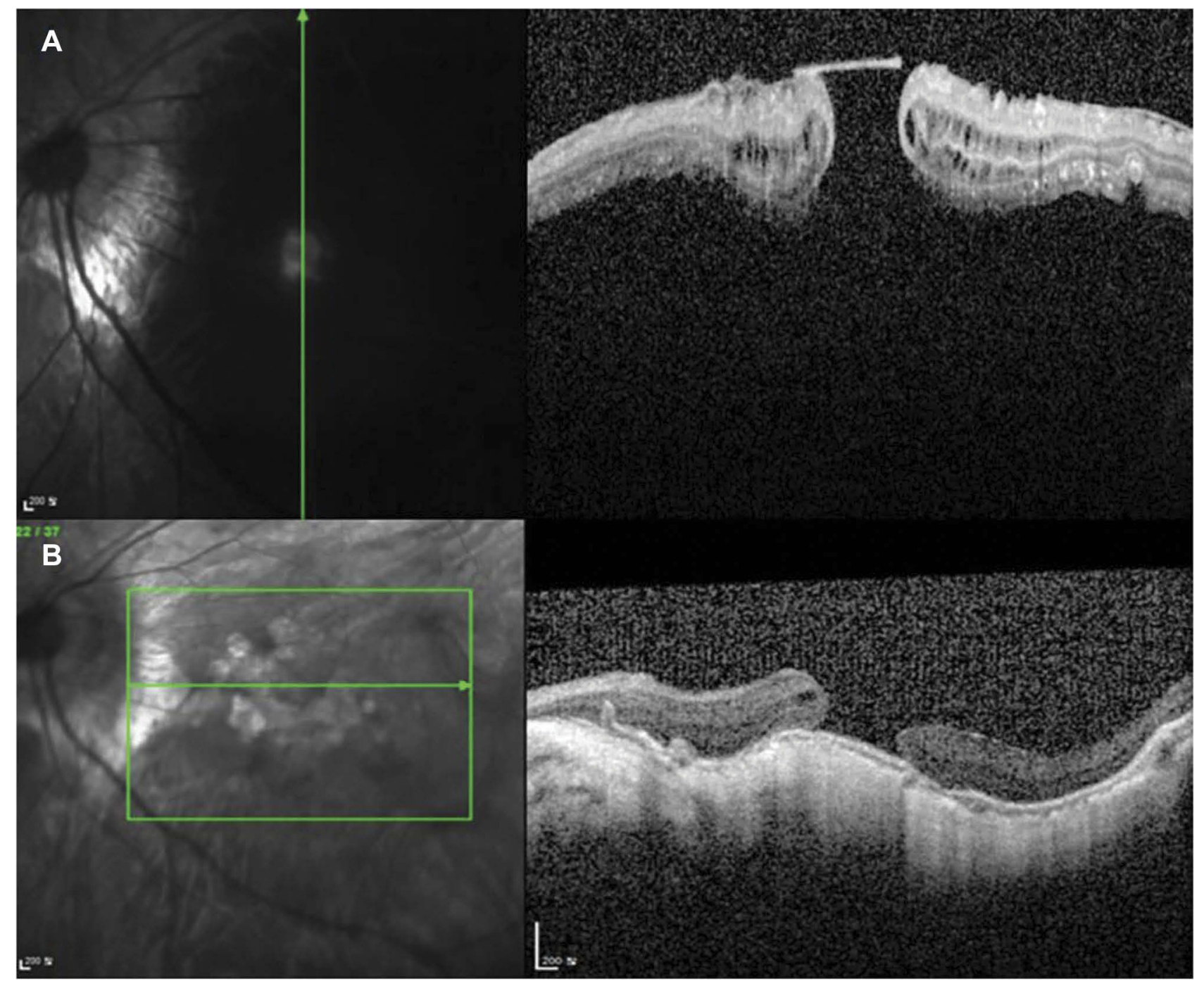

Figure 4 Pre- and postoperative OCT image of a 7I-year-old woman (case I). (A) MHRD with ERM is seen on preoperative OCT. The excavation of the posterior sclera was too deep to be captured simultaneously. (B) 30 months postoperative OCT shows reattachment of the retina with persistent MH. The buckle effect is well noticed on the OCT.

techniques were also introduced to aid the positioning of the buckle below the MH. ${ }^{13-15}$ Transillumination of the exoplant under the fovea enables correct positioning of the exoplant. The surgical technique of $\mathrm{MB}$ is still progressing and Bedda et $\mathrm{al}^{14}$ suggested using sterile topical adhesive to fix the buckle under the fovea. This could prevent events of scleral perforation or bleeding due to suture placement.

Many previous reports on $\mathrm{MB}$ required disinsertion of the extraocular muscles to suture the exoplant ${ }^{16-18}$ or lateral canthotomy was performed to obtain a sufficient surgical area. ${ }^{19}$ Diverse techniques of $\mathrm{MB}$ have been reported to avoid any damage to extraocular muscles; MB using Ando plombe $^{20,21}$ or many modified exoplants sutured the exoplant distant from the macular area after passing the exoplant behind the posterior segment. ${ }^{7,12,22,23}$ In this pilot study, we made a snail-tipped exoplant with materials easily available at the operation room for MB for treatment of MHRD in myopic eyes. Previously, Parolini et al ${ }^{24}$ introduced a L-shaped MB prepared with a $7 \times 5 \mathrm{~mm}$ silicone sponge (Labtician 507 oval sponge) strengthened with a malleable titanium stent $(15 \times 2 \times$ $0.5 \mathrm{~mm}$ ) and Mortada ${ }^{25}$ made a L-shaped exoplant with a $7 \mathrm{~mm}$ silicone sponge strengthened with a U-shaped $0.5 \mathrm{~mm}$ orthodontics stainless steel wire. Distinct from their L-shaped buckle, we rolled the end of the malleable titanium plate reinforced silicone sponge like a snail shell to enhance the buckle effect on the macular area. This shape can also prevent the exposure of titanium plate at the tip of the exoplant. Increased buckle height and volume could effectively press on to the macular area while anchoring the exoplant at a single quadrant distant from the posterior segment. 


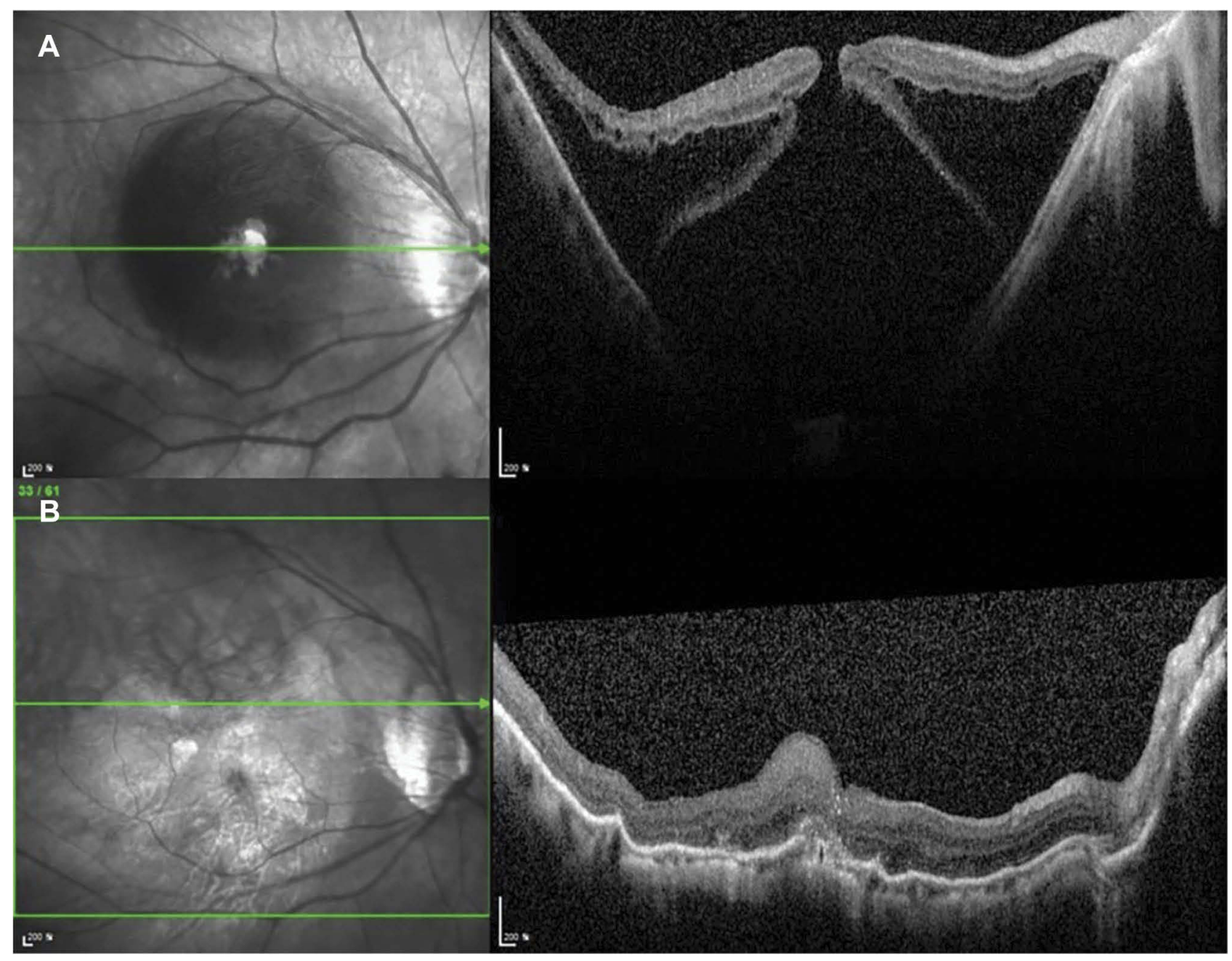

Figure 5 Pre- and postoperative OCT image of a 6I-year-old woman (case 4). (A) Preoperative OCT shows a high myopic eye with MHRD and PS. (B) 24 months postoperative OCT shows flattening of the posterior sclera with $\mathrm{MH}$ closure and retinal reattachment.

In earlier studies comparing PPV to MB, Ripandelli et al ${ }^{17}$ compared PPV to MB in 30 eyes with high myopic MHRD. In their study, MB showed better anatomic and functional outcomes than PPV. When comparing MB to combined PPV with MB, Parolini et $\mathrm{al}^{26}$ retrospectively reviewed 50 eyes of myopic traction maculopathy that underwent PPV with MB or MB alone. They reported MB alone was faster, safer, easier and as effective as combined surgery and suggested that MB alone should be the first procedure for all cases of myopic traction maculopathy. PPV with MB was recommended only in cases of significant tangential tractions. Mura et $\mathrm{al}^{7}$ performed additional MB in previously vitrectomized eyes and combined PPV with MB in naïve cases of $\mathrm{MH}$, macular schisis and MHRD. They reported combined PPV with MB should be performed in both naïve and recurrent cases of MHRD. In a prospective, randomized controlled study comparing PPV to combined PPV with MB in 98 eyes of high myopic MHRD, combined surgery showed better outcome. ${ }^{22}$ Burés-Jelstrup et $\mathrm{al}^{21}$ performed combined PPV with $\mathrm{MB}$ in high myopic eyes with $\mathrm{MH}$ and associated foveoschisis. They reported that MH closure was achieved in all cases of $\mathrm{MH}$ with associated foveoschisis. Alkabes et $\mathrm{al}^{20}$ performed combined PPV with MB in eyes with naïve and recurrent MHRD. They also reported high anatomical success rate and good functional results both in cases of naïve and recurrent high myopic MHRD. Recently, in a publication comparing PPV to MB in a 16-year review of literature, complete resolution of foveoschisis, $\mathrm{RD}$, and $\mathrm{MH}$ closure was achieved more frequently with MB than PPV. ${ }^{8}$

The advantages of combined PPV with MB compared to PPV alone are the ability to reattach the retina, to prevent redetachment of the retina and high rates of MH closure. ${ }^{26}$ In our pilot study, retinal reattachment was achieved in all cases and $\mathrm{MH}$ closure was confirmed in $75 \%$ of the cases. Even 


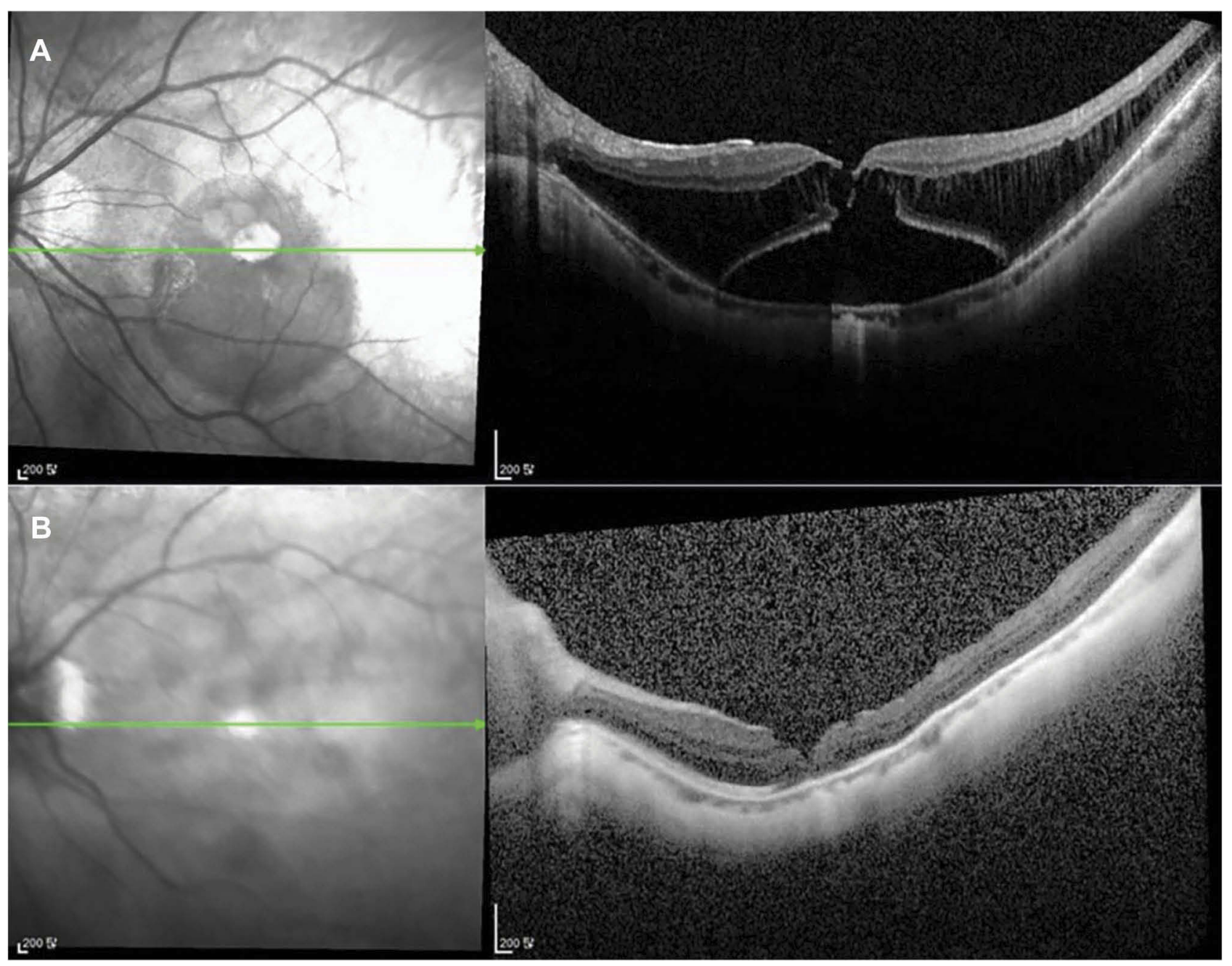

Figure 6 Pre- and postoperative OCT image of a 55-year-old woman (case 7). (A) Preoperative OCT shows foveal detachment and retinoschisis with MH. (B) II months after the surgery, $\mathrm{MH}$ closure was achieved with decreased bulging of the posterior scleral wall was seen on postoperative OCT.

though there was no significant improvement of postoperative BCVA which was probably affected by the associated myopic macular degenerations and SO tamponade status in addition to the persistent $\mathrm{MH}$, there was no recurrence of MHRD or any complications related to the exoplant material in any of the cases; the longest follow-up was up to 30 months. The exoplant materials are readily available, inexpensive and it is easy to make the snail-tipped shape in the operation room. We used smaller sized silicone sponge $(5 \mathrm{~mm})$ than previously reported similar exoplants that used $7 \mathrm{~mm}$ silicone sponge for exoplant material. ${ }^{24,25}$ This could also be advantageous in minimizing ocular motility limitations. The procedure of MB is quite simple, easy to learn and minimally invasive without the risk of any damage to the extraocular muscles. Placing sutures away from the posterior pole also prevents hazardous complications such as globe perforation or massive hemorrhage.
The limitations are the retrospective design, small sample size and relatively short follow-up period. Because it was a retrospective study, postoperative AL measurements were not available in all cases. Angiographic exams were not performed postoperatively to evaluate any ischemic changes in the posterior pole caused by the exoplant that may have affected the visual recovery. Also, up to date there is no report about the safety or stability issue of the titanium plate in the orbital area. Decrease in buckle height by lapse of time could be possible and chafing of the thin posterior scleral wall may happen by the mobile short arm of the exoplant that is not directly fixed to the sclera. Further comparative or controlled studies with larger sample size and longer follow-up period are required for this matter. However, in conclusion, combined PPV with MB using this new design of macular exoplant could be effective in treatment of MHRD. It is not necessary in all cases of MHRD but 


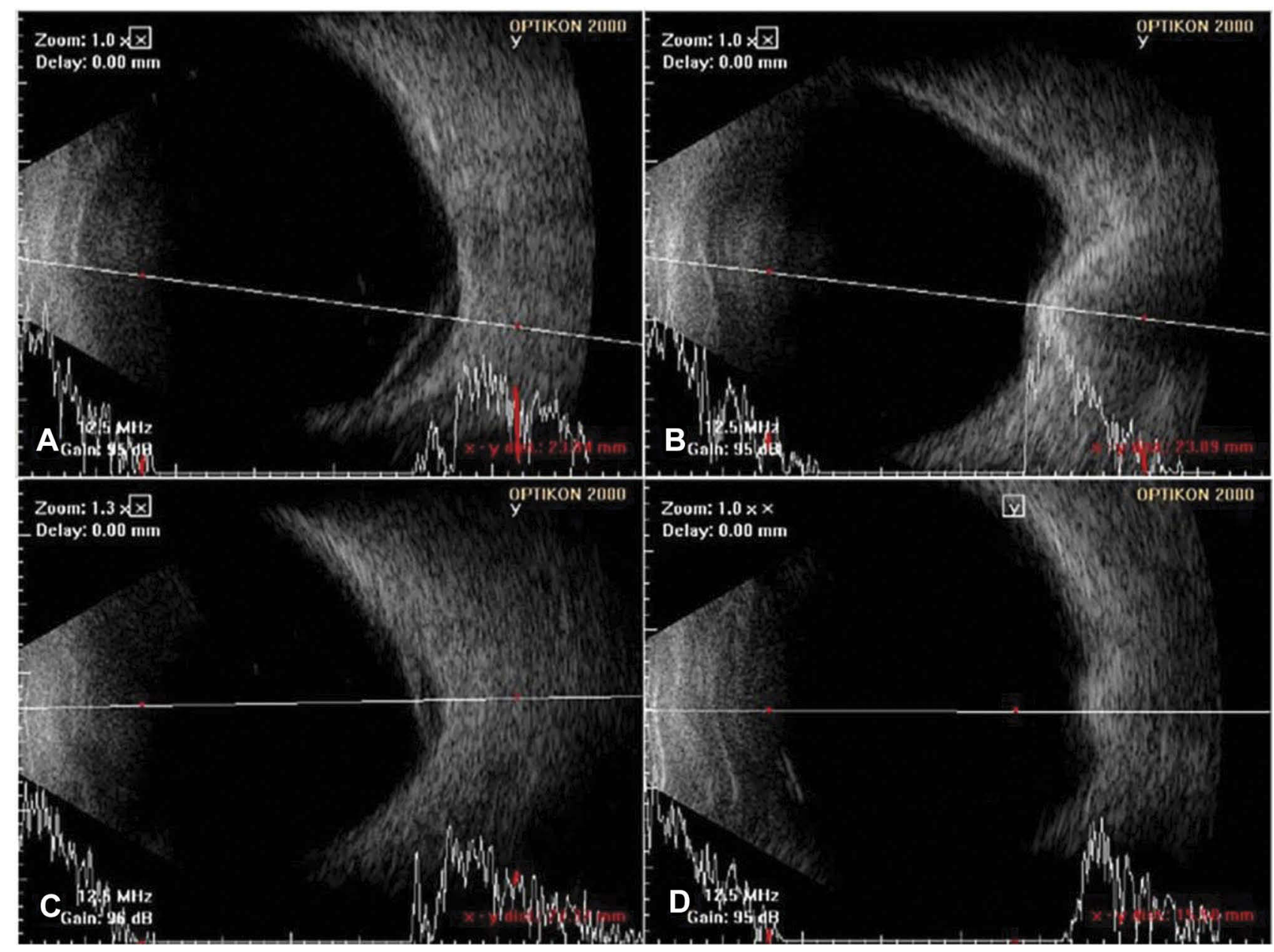

Figure 7 Pre- and postoperative B-scan USG images. (A) Preoperative B-scan USG image shows PS with retinal detachment (case 3). (B) Postoperative B-scan USG image shows correction of PS with indentation of the posterior sclera due to macular buckle effect (case 3). (C) Preoperative B-scan USG image shows PS with retinal detachment (case 4). (D) Postoperative B-scan USG image shows correction of PS with indentation of the posterior sclera due to macular buckle effect (case 4).

MB is profitable in cases that show prominent PS at the posterior pole especially at the macular area. MB has benefits over ILM flap technique in reshaping and flattening of the globe which can only be achieved by MB.

\section{Disclosure}

This study was supported by the Soonchunhyang University Research Fund. The sponsor or funding organisation had no role in the design or conduct of this research. This paper was presented at the 19th European VitreoRetinal Society (EVRS) meeting as a conference talk with interim findings. The authors report no conflicts of interest in this work.

\section{References}

1. Akiba J, Konno S, Yoshida A. Retinal detachment associated with a macular hole in severely myopic eyes. Am J Ophthalmol. 1999;128 (5):654-655. doi:10.1016/S0002-9394(99)00240-8
2. Takano M, Kishi S. Foveal retinoschisis and retinal detachment in severely myopic eyes with posterior staphyloma. Am J Ophthalmol. 1999;128(4):472-476. doi:10.1016/S0002-9394(99)00186-5

3. Stirpe M, Michels RG. Retinal detachment in highly myopic eyes due to macular holes and epiretinal traction. Retina. 1990;10(2):113-114. doi:10.1097/00006982-199004000-00004

4. Gonvers M, Machemer R. A new approach to treating retinal detachment with macular hole. Am J Ophthalmol. 1982;94(4):468-472. doi:10.1016/0002-9394(82)90240-9

5. Shukla D, Dhawan A. Foveoschisis after vitrectomy for myopic macular hole with secondary retinal detachment. Eye (Lond). 2009;23(11):2124-2125. doi:10.1038/eye.2008.405

6. Schepens CL, Okamura ID, Brockhurst RJ. The scleral buckling procedures. I. Surgical techniques and management. AMA Arch Ophthalmol. 1957;58(6):797-811. doi:10.1001/archopht.1957.00940 010819003

7. Mura M, Iannetta D, Buschini E, de Smet MD. T-shaped macular buckling combined with $25 \mathrm{G}$ pars plana vitrectomy for macular hole, macular schisis, and macular detachment in highly myopic eyes. Br J Ophthalmol. 2017;101(3):383-388. doi:10.1136/bjophthalmol-2015-308124

8. Alkabes M, Mateo C. Macular buckle technique in myopic traction maculopathy: a 16-year review of the literature and a comparison with vitreous surgery. Graefes Arch Clin Exp Ophthalmol. 2018;256 (5):863-877. doi:10.1007/s00417-018-3947-3 
9. Nakanishi H, Kuriyama S, Saito I, et al. Prognostic factor analysis in pars plana vitrectomy for retinal detachment attributable to macular hole in high myopia: a multicenter study. Am J Ophthalmol. 2008;146 (2):198-204. doi:10.1016/j.ajo.2008.04.022

10. Sebag J. Anomalous posterior vitreous detachment: a unifying concept in vitreo-retinal disease. Graefes Arch Clin Exp Ophthalmol. 2004;242(8):690-698. doi:10.1007/s00417-004-0980-1

11. Enaida H, Hata Y, Ueno A, et al. Possible benefits of triamcinoloneassisted pars plana vitrectomy for retinal diseases. Retina. 2003;23 (6):764-770. doi:10.1097/00006982-200312000-00003

12. Wu PC, Sheu JJ, Chen YH, et al. Gore-tex vascular graft for macular buckling in high myopia eyes. Retina. 2017;37(7):1263-1269.

13. Sonmez K, Keles A. Macular buckling surgery for Retinal Detachment Associated with macular hole in high myopia eye. Turk J Ophthalmol. 2017;47(6):351-354. doi:10.4274/tjo

14. Bedda AM, Abdel Hadi AM, Lolah M, Abd Al Shafy MS. A new sutureless illuminated macular buckle designed for myopic macular hole retinal detachment. J Ophthalmol. 2017;2017:6742164.

15. Mateo C, Dutra Medeiros M, Alkabes M, Bures-Jelstrup A, Postorino M, Corcostegui B. Illuminated Ando plombe for optimal positioning in highly myopic eyes with vitreoretinal diseases secondary to posterior staphyloma. JAMA Ophthalmol. 2013;131(10):1359-1362. doi:1 0.1001/jamaophthalmol.2013.4558

16. Park DY, Kim JH, Ha HS, Kang SW. The macular buckling procedure for Retinal Detachment Associated with a macular hole in high myopia. J Korean Ophthalmol Soc. 2012;53(7):969-976. doi:10.334 $1 / \mathrm{jkos} .2012 .53 .7 .969$

17. Ripandelli G, Coppe AM, Fedeli R, Parisi V, D’Amico DJ, Stirpe M. Evaluation of primary surgical procedures for retinal detachment with macular hole in highly myopic eyes: a comparison [corrected] of vitrectomy versus posterior episcleral buckling surgery. Ophthalmology. 2001;108(12):2258-2264; discussion 2265. doi:10.1016/S0161-6420 (01)00861-2

18. Siam AL, El Maamoun TA, Ali MH. Macular buckling for myopic macular hole retinal detachment: a new approach. Retina. 2012;32 (4):748-753. doi:10.1097/IAE.0b013e3182252a75
19. Tanaka T, Ando F, Usui M. Episcleral macular buckling by semirigid shaped-rod exoplant for recurrent retinal detachment with macular hole in highly myopic eyes. Retina. 2005;25(2):147-151. doi:10.10 97/00006982-200502000-00005

20. Alkabes M, Bures-Jelstrup A, Salinas C, et al. Macular buckling for previously untreated and recurrent retinal detachment due to high myopic macular hole: a 12-month comparative study. Graefes Arch Clin Exp Ophthalmol. 2014;252(4):571-581. doi:10.1007/s00417013-2497-y

21. Bures-Jelstrup A, Alkabes M, Gomez-Resa M, Rios J, Corcostegui B, Mateo C. Visual and anatomical outcome after macular buckling for macular hole with associated foveoschisis in highly myopic eyes. $\mathrm{Br}$ J Ophthalmol. 2014;98(1):104-109. doi:10.1136/bjophthalmol-2013304016

22. Ma J, Li H, Ding X, Tanumiharjo S, Lu L. Effectiveness of combined macular buckle under direct vision and vitrectomy with ILM peeling in refractory macular hole retinal detachment with extreme high axial myopia: a 24-month comparative study. Br J Ophthalmol. 2017;101 (10):1386-1394. doi:10.1136/bjophthalmol-2016-310123

23. Theodossiadis GP, Theodossiadis PG. The macular buckling procedure in the treatment of retinal detachment in highly myopic eyes with macular hole and posterior staphyloma: mean follow-up of 15 years. Retina. 2005;25(3):285-289. doi:10.1097/00006982-20050400 0-00006

24. Parolini B, Frisina R, Pinackatt S, Mete M. A new L-shaped design of macular buckle to support a posterior staphyloma in high myopia. Retina. 2013;33(7):1466-1470. doi:10.1097/IAE.0b013e31828e69ea

25. Mortada HA. A novel episcleral macular buckling: wire-strengthened sponge exoplant for recurrent macular hole and retinal detachment in high myopic eyes. Med Hypothesis Discov Innov Ophthalmol. 2013;2 (1):14-19.

26. Parolini B, Frisina R, Pinackatt S, et al. Indications and results of a new 1-shaped macular buckle to support a posterior staphyloma in high myopia. Retina. 2015;35(12):2469-2482. doi:10.1097/IAE.000 0000000000613
Clinical Ophthalmology

\section{Publish your work in this journal}

Clinical Ophthalmology is an international, peer-reviewed journal covering all subspecialties within ophthalmology. Key topics include: Optometry; Visual science; Pharmacology and drug therapy in eye diseases; Basic Sciences; Primary and Secondary eye care; Patient Safety and Quality of Care Improvements. This journal is indexed on PubMed

\section{Dovepress}

Central and CAS, and is the official journal of The Society of Clinical Ophthalmology (SCO). The manuscript management system is completely online and includes a very quick and fair peer-review system, which is all easy to use. Visit http://www.dovepress.com/ testimonials.php to read real quotes from published authors. 